\title{
Cyclical etidronate increases bone density in the spine and hip of postmenopausal women receiving long term corticosteroid treatment. A double blind, randomised placebo controlled study
}

Piet Geusens, Jan Dequeker, Johan Vanhoof, Rita Stalmans, Steven Boonen, Jo Joly, Jos Nijs, Jef Raus

\begin{abstract}
Objective-To study the effect of cyclic etidronate in secondary prevention of corticosteroid induced osteoporosis.

Methods-A double blind, randomised placebo controlled study comparing cyclic etidronate and placebo during two years in 37 postmenopausal women receiving long term corticosteroid treatment, mainly for polymyalgia rheumatica $(40 \%$ of the patients) and rheumatoid arthritis $(30 \%)$. Bone density was measured in the lumbar spine, femoral neck, and femoral trochanter.

Results-After two years of treatment there was a significant difference between the groups in mean per cent change from baseline in bone density in the spine in favour of etidronate $(p=0.003)$. The estimated treatment difference (mean (SD)) was $9.3(2.1) \%$. Etidronate increased bone density in the spine $(4.9(2.1) \%, p<0.05)$ whereas the placebo group lost bone $(-2.4$ (1.6)\%). At the femoral neck there was an estimated difference of $5.3(2.6) \%$ between the groups (etidronate: $3.6(1.4) \%, p<0.05$, placebo: $-2.4(2.1) \%)$. The estimated difference at the trochanter was 8.2 (3.0) (etidronate: $9.0(1.5) \%, p<0.0001$, placebo: $0.5(2.3) \%)$. No significant bone loss occurred in the hip in placebo treated patients.
\end{abstract}

Conclusions-Cyclic etidronate is an effective treatment for postmenopausal women receiving corticosteroid treatment and is well tolerated.

(Ann Rheum Dis 1998;57:724-727)

Arthritis and

Metabolic Bone

Disease Research Unit,

K U Leuven, Belgium

J Dequeker

J Joly

J Nijs

Department of

Geriatric Medicine,

K U Leuven, Belgium

$S$ Boonen

Correspondence to:

Professor P Geusens, Dr L

Willems-Intituut, Limburgs

Universitair Centrum,

B-3590 Diepenbeek,

Belgium.

Accepted for publication 3 September 1998 blind placebo controlled trials on primary prevention of CIOP indicate a protective effect of calcitriol ${ }^{9}$ and etidronate ${ }^{10}$ but not of calcium and vitamin D. ${ }^{11}$ Double blind studies on the secondary prevention are scarce ${ }^{12-14}$ and indicate a significant effect of bisphosphonates compared with placebo ${ }^{12}$ but not of vitamin D. ${ }^{14}$ Results on alendronate in CIOP show similar results. ${ }^{15}$ In a number of preliminary, open studies, increases in bone density were found with inhibitors of bone resorption, such as bisphosphonates, in the spine $\mathrm{e}^{16-20}$ and hip. ${ }^{16}$ However, no double blind studies are available on the effect of secondary prevention on bone density in the hip. Postmenopausal women were studied as they are more at risk for developing CIOP with fractures. ${ }^{10}$

We therefore studied, in a double blind placebo controlled study, the effect of cyclic etidronate and calcium on bone in the spine and hip of postmenopausal women receiving long term corticosteroid treatment mainly for rheumatological conditions.

\section{Methods}

In total, 37 patients receiving long term corticosteroid treatment were entered in the study. Figure 1 shows the trial profile. The study was approved by the local ethical committee. Patients were consecutively recruited from two university centres when they consented to participate in the study (12 placebo and 12 etidronate patients in centre 1 and 7 placebo and 6 etidronate patients in centre 2). They were randomly assigned (in blocks of two within each centre) to treatment with cyclic etidronate $(400 \mathrm{mg} /$ day in the morning, two hours from meals) $(\mathrm{n}=18)$ or placebo $(n=19)$ for two weeks, followed by calcium 500 $\mathrm{mg} /$ day in the evening for 11 weeks. This three month cycle was repeated for two years. Etidronate was given in tablets and the placebo tablets were similar in taste and appearance. The code was located in the sponsor's office and was only broken after full statistical analysis. Blinding was successful among participants, doctors, data managers, and statisticians. No patients were taking hormonal replacement therapy. All patients were postmenopausal and were receiving corticosteroid equivalent to 5 to $20 \mathrm{mg}$ prednisolone per day for more than three months. The duration of coticosteroid treatment before the start of the study was extremely skewed and was similar between the two groups (median 31 months (range 3-108) in the placebo treated patients and 45 months (range 3-503 months) in the 


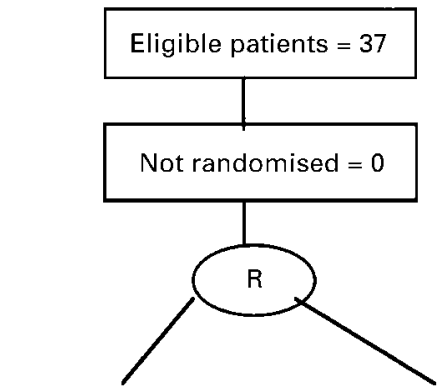

Placebo

Etidronate
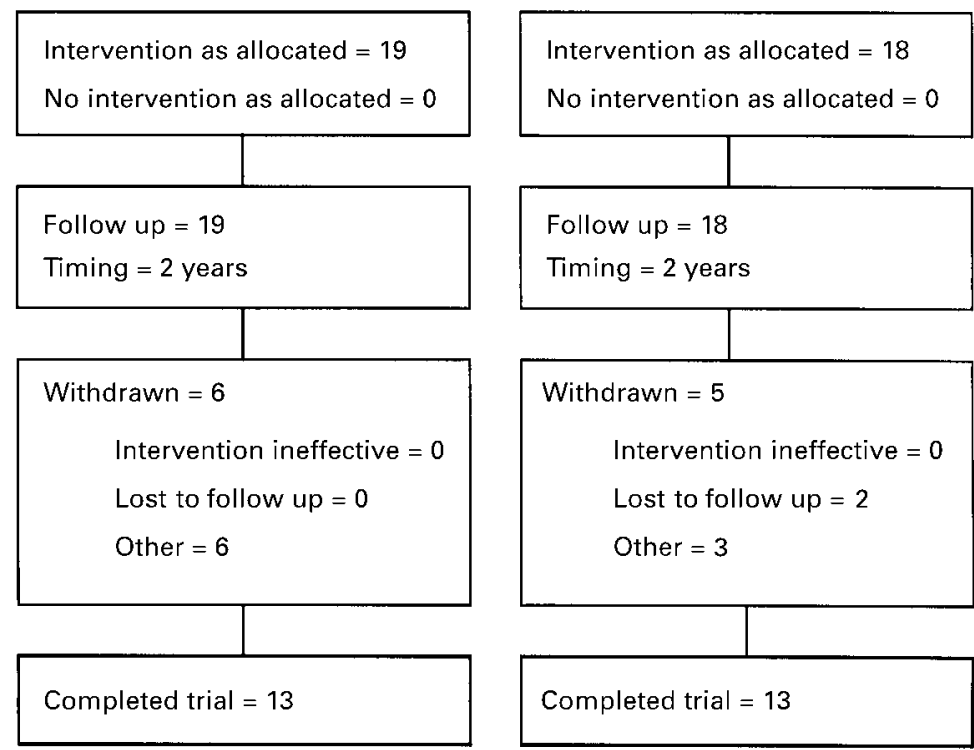

Figure 1 Flow diagram of the trial, with numbers of patients.

etidronate treated patients, $\mathrm{p}=0.064$ using Wilcoxon-Mann-Whitney test). The indications for corticosteroids were rheumatoid arthritis (placebo: $n=9$, etidronate: $n=3$ ), polymyalgia rheumatica (placebo: $n=5$, etidronate: $\mathrm{n}=10$ ), osteoarthritis (placebo: $\mathrm{n}=1$ ), chronic bronchitis (placebo: $n=3$, etidronate: $n=2$ ), inflammatory gastrointestinal diseases without osteomalacia (etidronate: $\mathrm{n}=2$ ), idiopathic eosinophilia (placebo: $\mathrm{n}=1$ ) and sarcoidosis (etidronate: $n=1$ ). Patients were examined by a rheumatologist every three months for adaptation of the dose of corticosteroid, according to the common clinical practice. Bone density was measured by dual energy $x$ ray based absorptiometry using DPX-L (Lunar Inc) or QDR 2000 (Hologic Inc). All patients were followed

Table 1 Baseline clinical and bone density data (mean (SD)). The numbers of patients for each variable are indicated

\begin{tabular}{lll}
\hline Variable & Placebo & Etidronate \\
\hline Patients (n) & 19 & 18 \\
Age (y) & $65(10)(19)$ & $63(6)(18)$ \\
Years since menopause (y) & $19(11)(19)$ & $13(9)(18)$ \\
Weight (kg) & $69(11)(19)$ & $63(7)(18)$ \\
Height (cm) & $160(6)(19)$ & $157(6)(18)$ \\
Mean prednisolone dose (mg/day) & $6.35(3.58)(17)$ & $6.27(2.99)(18)$ \\
Z score & & $-1.10(1.02)(18)$ \\
$\quad$ Lumbar spine & $-0.87(0.89)(18)$ & $-0.98(0.74)(18)$ \\
$\quad$ Femoral neck & $-0.91(0.75)(17)$ & \\
T score & $-2.47(0.60)(18)$ & $-2.82(1.12)(17)$ \\
$\quad$ Lumbar Spine & $-2.11(1.22)(15)$ & $-2.14(0.86)(17)$ \\
$\quad$ Femoral Neck & & \\
\hline
\end{tabular}

up on the same device during the study. Bone density was measured at baseline and every six months in the lumbar spine in vertebrae L2 to L4, in the left femoral neck and in the left femoral trochanter according to the manufacturer's instructions. Bone density was not evaluated in the Ward's triangle as the procedure to locate the Ward's triangle is different between the devices. Precision was $<1 \%$ in the spine and $<2.5 \%$ in the hip for both devices. All data were centrally collected and blindly controlled for inadequate delineation and other errors. For comparison at baseline, bone density was expressed in $\mathrm{T}$ scores, one $\mathrm{T}$ score is one standard deviation difference from the mean of healthy young women, as provided by the manufacturer and in $\mathrm{Z}$ scores, one $\mathrm{Z}$ score is one standard deviation difference from the mean of age and sex matched healthy women, as provided by the manufacturer. Manufacturer provided normal values for $\mathrm{Z}$ and $T$ scores in the spine were similar for both devices compared with a local control population. In some patients $\mathrm{Z}$ scores (one in spine and two in the femoral neck) or $\mathrm{T}$ scores (one in spine and four in the femoral neck) were not available from the DEXA device at baseline. During follow up, data were expressed in per cent change from baseline, based on bone density in $\mathrm{g} / \mathrm{cm}^{2}$.

Clinical symptomatic fractures that were confirmed by qualitative analysis of the radiographs of the thoracic and lumbar spine (that were taken systematically at baseline and after one and two years) were recorded. Occurrence of all adverse events was recorded regardless of relation to study drug. Daily corticosteroid intake during the study was calculated as the cumulative dose devised by the number of days of intake.

\section{STATISTICS}

Descriptive statistics were used to compare the groups at baseline with respect to patient characteristics and other baseline characteristics (age, years since menopause, daily corticosteroid use, indications for corticosteroids, bone density of spine and hip, serum and urinary bone markers). The primary analysis was a comparison between the treatment groups by an analysis of covariance of the spinal bone density per cent change from baseline at two years for the intent to treat population. ${ }^{21}$ The mean corticosteroid dose over the two years was used as the covariate adjustment. A term for study centre was also fitted in the ANCOVA model, correcting for the two centres and the use of different devices (DPX-L and QDR 2000). Similar analyses were performed for hip bone density. To aid analysis, within group analyses of per cent changes from baseline were performed.

\section{Results}

Table 1 shows the baseline clinical data, bone density, and biochemical data. Mean age, years since menopause, daily corticosteroid dose, and bone density (expressed in $\mathrm{Z}$ and $\mathrm{T}$ scores) were similar in both treatment groups. $Z$ scores were different from zero in the spine and hip 

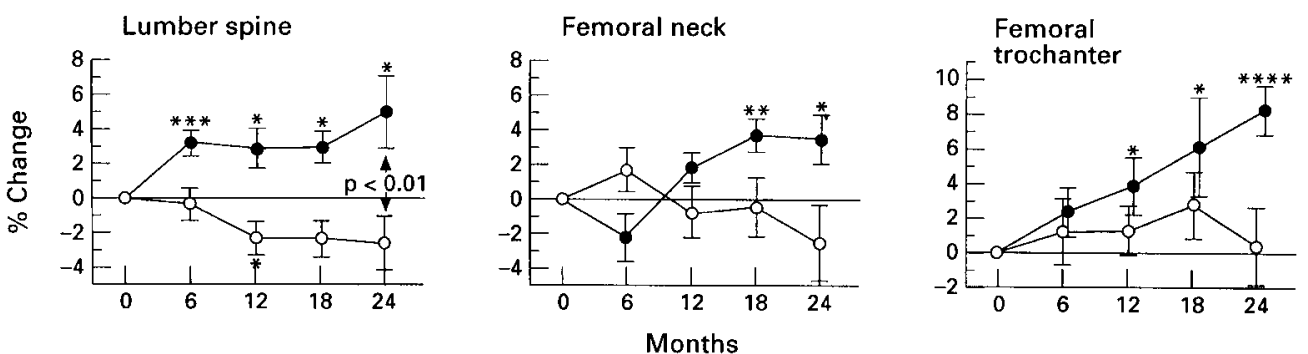

Figure 2 Per cent changes (compared with baseline, mean (SEM)) bone density in the lumbar spine, femoral neck, and femoral trochanter in the etidronate (closed circles) and placebo (open circles) treated groups. ${ }^{\star} p<0.05,{ }^{\star} p<0.01,{ }^{\star} \star \star$ $p<0.001,{ }^{\star \star \star *} p<0.0001$ compared with baseline.

$(\mathrm{p}<0.05$ in both treatment groups). Of the initial 37 patients, 11 patients were withdrawn for the following reasons: adverse events (anaphylactic shock (placebo: $n=1$ ), shoulder fracture (placebo: $\mathrm{n}=1)$ ), protocol violation (placebo: $\mathrm{n}=2$, etidronate: $\mathrm{n}=2$ ), non-compliance (placebo: $n=2$ ), personal reasons (etidronate: $n=2$ ) and death because of a ruptured aortic aneurysm after a long history of arteritis (etidronate: $\mathrm{n}=1$ ). The mean daily corticosteroid intake (mean (SD)) before the study was 6.4 (0.9) $\mathrm{mg}$ /day in the placebo group and 6.3 (0.7) $\mathrm{mg} /$ day in the etidronate group (no differences between the groups). During the study the mean daily corticosteroid intake was not significantly different between the treatment groups $(5.5(0.7) \mathrm{mg} /$ day in the etidronate group and $4.7(0.8) \mathrm{mg} /$ day in the placebo group).

After two years of treatment there was a significant difference between the groups in mean per cent change from baseline in spinal bone density favour of etidronate $(p=0.003)$. The estimated treatment difference (mean (SD)), adjusted for corticosteroid dose and study centre was $9.3(2.1) \%$. The etidronate group increased bone density $(4.9(2.1) \%, \mathrm{p}<0.05)$ and the placebo group lost bone $(-2.4(1.6) \%$, not significant) (fig 2). At the femoral neck there was an estimated difference of $5.3(2.6) \%$ (not significant) between the groups (etidronate: $3.6(1.4) \%$, p<0.05, placebo: -2.4 (2.1), not significant). The estimated difference at the trochanter was 8.2 (3.0) (not significant) (etidronate: 9.0 (1.5), $\mathrm{p}<0.0001$, placebo: 0.5 (2.3)\%, not significant). There was no consistent relation at the different sites between corticosteroid dose and per cent change in bone density.

Clinical symptomatic and radiological confirmed fractures occurred in five $(28 \%)$ patients receiving placebo (hip: $n=2$, shoulder: $n=1$, foot: $n=1$, vertebra T5: $n=1$ ) and in one $(6 \%)$ patient on etidronate (hip: $n=1$ ). None of the fractures occurred as a result of excess force. In the one patient that developed acute back pain and in whom radiography of the spine was therefore performed, the 5th thoracic vertebra was decreased by $>50 \%$ compared with the 6 th thoracic vertebra. The relative risk for fracture was not significant for etidronate compared with placebo $(0.21,95 \%$ confidence intervals: $0.03,1.64)$.

The treatment was well tolerated. Gastrointestinal side effects were reported by four patients receiving placebo (diarrhoea: $n=2$, nausea: $n=1$, vomiting: $n=1$ ) and three receiving etidronate (nausea: $n=2$, vomiting: $n=1$ ). No differences were found in side effects reported for other organ systems (data not shown).

\section{Discussion}

This is the first double blind placebo controlled study on treatment of CIOP in both the spine and the hip. The effect of cyclic etidronate was studied in postmenopausal women receiving long term corticosteroid treatment who had already lost bone, as reflected by a low $\mathrm{T}$ score and low $\mathrm{Z}$ score. ${ }^{9}$ The low $\mathrm{Z}$ scores reflect the additional effect of corticosteroid and/or disease activity on bone loss in postmenopausal women. In these patients, bone density was significantly different in the spine in favour of etidronate and the same trends were found in the hip. The changes in bone density in the spine were not influenced by fracture healing, as no clinical symptomatic fractures occurred in the lumbar spine and no manifest qualitative radiological signs of fracture were found on radiographs of the spine that were performed at baseline and after one and two years. A positive effect on the hip is an important clinical finding, as the risk of hip fractures is doubled in patients treated with corticosteroids. ${ }^{7}$ The finding of positive effects on both femoral neck and the trochanteric region further emphasises the potential of etidronate to reduce corticosteroid induced bone loss in both cortical and trabecular bone. Also in primary prevention of CIOP etidronate inhibited bone loss in the spine and the trochanter, and this was accompanied by a significant reduction of new vertebral fractures. ${ }^{10}$ In this study, the effect of etidronate on total fracture was not significant, but this study was not designed to allow analysis of fracture rate. These results on BMD are in accordance with open studies of bisphosphonates, such as etidronate alone ${ }^{16171921}$ or combined with calcium and vitamin $\mathrm{D},{ }^{23}$ showing an increase of bone density in the spine $e^{16171922}$ and hip. ${ }^{16}$ Pamidronate increased bone density in the spine. ${ }^{12}$ The effects on cortical bone are contradictory. ${ }^{18} 20$ The increase in bone density in the spine and trochanter after etidronate was more pronounced than in primary prevention of CIOP. ${ }^{10}$ This can be attributable to the much lower dose of corticosteroids in this study (6 $\mathrm{mg}$ of prednisolone/day) as compared with the study of Adachi et al $(>20 \mathrm{mg}$ of prednisolone/day). ${ }^{17}$ Furthermore, bone loss is less pronounced during long term corticosteroid 
treatment as compared with immediately after the start of corticosteroids ${ }^{8}$ and therefore possibly more modifiable as shown in this study.

Therefore, and because most patients receiving long term corticosteroid treatment do not take prophylaxis, ${ }^{1}$ the results of treatment with etidronate are encouraging as etidronate was not only able to stop bone loss but also to increase significantly bone density in the spine and hip. The increase in bone density was similar as in postmenopausal women without corticosteroid treatment. ${ }^{24}$ The patients taking calcium alone did not significantly lose bone, except after 12 months in the spine, but not in the femoral neck or trochanter. Therefore, it can be assumed that long term low dose corticosteroids in postmenopausal women is not accompanied by bone loss in the femur when calcium supplements are prescribed. However, in these patients no bone gain was achieved with calcium alone, in contrast with the effect of etidronate, which increased significantly bone density in the spine, femoral neck, and trochanter.

Placebo treated patients, taking $500 \mathrm{mg}$ calcium per day in the evening, did not significantly lose bone, except during the first 12 months in the spine. Other studies have shown that calcium supplements given in the evening can diminish bone turnover in patients treated with corticosteroids, ${ }^{23}$ and can decrease bone loss in the forearm ${ }^{13}$ but not in the hip. ${ }^{16}$ The results in the spine are conflicting. ${ }^{16}{ }^{17} 26 \mathrm{Al}$ though the number of patients was small, the results of this study indicate that calcium supplements alone are not accompanied by bone loss in postmenopausal women taking low dose corticosteroids.

Several aspects of the study require further discussion. Firstly, the drop out rate of $29.7 \%$ may seem high, but this figure was similar to other published studies on CIOP prevention given its duration. ${ }^{9-11} 13$ Secondly, the small sample size can raise concerns over the statistical power. Retrospective power calculations showed the study to have $90 \%$ power to detect $7-8 \%$ treatment differences at two years for the different skeletal sites. Therefore, the study was powered to detect clinically meaningful effects on BMD. Thirdly, biochemical parameters that are now available to monitor bone formation and resorption, such as N-telopeptides and deoxypyridinoline, were not available for this study. Fourthly, there were more patients with rheumatoid arthritis in the placebo group. Patients with rheumatoid arthritis lose bone because of the disease process itself. ${ }^{27}$ However, at the dose of corticosteroids used in this study (6 mg of prednisolone/day), patients with rheumatoid arthritis are not expected to have an accelerated bone loss during corticosteroid treatment compared with patients taking corticosteroids for other diseases. ${ }^{27}$

We conclude that, as compared with placebo, treatment with cyclic etidronate increases bone density in secondary prevention of CIOP in patients predominantly with rheumatic conditions and was well tolerated.

This study was designed by the first author and supported by a grant from Procter and Gamble Pharmaceuticals, UK.
We thank S Pack and I Barton, Biostatistics and Medical Surveillance, Procter and Gamble Pharmaceuticals, UK, for statistical assistance and analysis.

1 Walsch LJ, Wong CA, Pringle M, Tattersfiel AE. Use of oral corticosteroids in the community and the prevention of secondary osteoporosis: a cross-sectional study. BMJ secondary osteop

2 Hahn TJ, Hahn BH. Osteopenia in subjects with rheumatic diseases. Semin Arthritis Rheum 1976;6:165-88.

3 Adinoff AD, Hollister JR. Steroid-induced fractures and bone loss in patients with asthma. N Engl J Med 1983;309: 265-8.

4 Hooyman JR, Melton LJ, Nelson AM, O'Fallon WM, Riggs BL. Fractures after rheumatoid arthritis. A populationbased study. Arthritis Rheum 1984;27:1353-61.

5 Butler RC, Davie MWJ, Worsfold M, Sharp CA. Bone mineral content in patients with rheumatoid arthritis: relationhip to low-dose steroid therapy. Br J Rheumatol 1991;30: 86-90.

6 Dykman TR, Gluck OS, Murphy WA, Hahn TJ, Hahn BH. Evaluation of factors associated with glucocorticoidinduced osteopenia in patients with rheumatic diseases. Athritis Rheum 1985;28:361-8.

7 Cooper C, Coupland C, Mitchell M. Rheumatoid arthritis, corticosteroid therapy and hip fracture. Ann Rheum Dis 1995;54:49-52.

8 Sambrook P, Birmingham J, Kempler S, Kelly P, Eberl S, Pocock N, et al. Corticosteroid effects on proximal femur loss. J Bone Miner Res 1990;5:1211-16.

9 Sambrook P, Birmingham J, Kelley P, Kempler S, Nguyen $\mathrm{T}$, Pocock N, et al. Prevention of corticosteroid osteoporosis - a comparison of calcium, calcitriol and calcitonin. $\mathrm{N}$ Engl J Med 1993;328:1747-52.

10 Adachi JD, Bensen WG, Brown J, Hanley D, Hodsman A, Josse R, et al. Intermittent etidronate therapy to prevent 337:382-7.

11 Adachi JD, Bensen WG, Bianchi F, Cividino A, Pillersdorf $\mathrm{S}$, Sebaldt RJ, et al. Vitamin D and calcium in the preven-
tion of corticosteroid induced osteoporosis: a 3 year followup. J Rheumatol 1996;23:995-1000.

12 Reid IR, Heap SW, King AR, Ibbertson HK. Two-year follow-up of bisphosphonate (APD) treatment in steroid

13 Dykman TR, Haralson KM, Gluck OS, Murphy WA, Teitelbaum SL, Hahn TJ, et al. Effect of oral 1.25dihydroxyvitamin D and calcium on glucocorticoidinduced osteopenia in subjects with rheumatic diseases. Arthritis Rheum 1984;27:1336-43.

14 Buckley LM, Leib ES, Cartularo KS, Vacek PM, Cooper SM. Calcium and vitamin D3 supplementation prevents bone loss in the spine secondary to low-dose corticosteroids in patients with rheumatoid arthritis. Ann Intern Med 1996;125:961-8

15 Saag KG, Emkey R, Schnitzer TJ, Brown JP, Hawkins F, Goemaere $\mathrm{S}$, et al. Alendronate for the prevention and treatment of glucocorticoid induced osteoporosis. Glucocorticoid-Induced Intervention Study Group. N Engl J Med 1998;339:292-9.

16 Struys A, Snelder AA, Mulder H. Cyclical etidronate reverses bone loss of the spine and proximal femur in patients with established corticosteroid-induced osteoporosis. Am J Med 1994;99:235-42.

17 Adachi JD, Cranney A, Goldsmith $\mathrm{CH}$, Bensen WG, Bianchi F, Cividino A, et al. Intermittent cyclic therapy with etidronate in the prevention of corticosteroid induced bone loss. J Rheumatol 1994;21:1922-6.

18 Gallacher SJ, Fenner JAK, Anderson K, Bryden FM, Banham $\mathrm{SW}$, Logue FC, et al. Intravenous pamidronate in the treatment of osteoporosis associated with corticosteroid dependent lung disease: an open pilot study.Thorax 1992;47:932-6.

19 Sebaldt RJ, Adachi JD, Bensen WG, Bianchi F, Cividano A, Craig GL, et al. Intermittent cyclic therapy with etidronate prevents corticosteroid-induced bone loss: two years of follow-up. Scand J Rheumatol 1996;25 (suppl 3):91-3.

20 Boutsen Y, Jamart J, Esselinckx W, Stoffel M, Devogelaer JP. Primary prevention of glucocorticoid-induced osteoporosis with intermittent intravenous pamidronate: a randomised with intermittent intravenous pamidron
trial. Calcif Tissue Int 1007;61:266-71.

21 Altman DG. Practical statistics for medical research. London: Altman DG. Practical statistics.

22 Mulder H, Struys A. Intermittent cyclical etidronate in the prevention of corticosteroid induced bone loss. Br J Rheumatol 1994;33:348-50.

23 Diamond T, McGuigan LM, Barbagallo S, Bryant C. Cyclical etidronate plus ergocalciferol prevents glucocorticoidnduced bone loss in postmenopausal women. Am J Med 1995;98:459-63.

24 Storm T, Thamsborg G, Steiniche T, Genant HK, Sorensen $\mathrm{OH}$. Effect of intermittent cyclical etidronate therapy on bone mass and fracture rate in women with postmenopausal osteoporosis. N Engl J Med 1990;322:1265-71.

25 Reid IR, Ibbertson HK. Calcium supplements in the prevention of steroid-induced osteoporosis. Am J Clin Nutr 1986;44:287-99.

26 Bijlsma JWJ, Raymakers JA, Mosch C Effect of oral calcium and vitamin D on glucocorticoid-induced osteopenia. Clin and vitamin D on glucocorticoid-in

27 Verhoeven AC, Boers M. Limited bone loss due to in rheumatoid arthritis and other diseases. J Rheumatol 1997;24:1495-503. 